\title{
La demanda de empleo en la industria manufacturera de México
}

\author{
The demand for employment in the manufacturing industry in Mexico
}

\author{
Rafael Tavares Luna* y Rogelio Varela Llamas
}

Universidad Autónoma de Baja California, México

Recibido el 31 de Octubre del 2016; aceptado el 07 de junio del 2018

Disponible en Internet el 10 de novembre de 2018

\section{Resumen}

El propósito del documento es analizar la demanda de empleo en la industria manufacturera de México, durante el periodo de 2007 a 2015, considerando 19 subsectores de la industria manufactura. Se analiza el efecto que tienen variables de desempeño económico como el producto interno bruto, así como los salarios. También se consideran como variables explicativas, la productividad laboral y las exportaciones de la manufactura. Con información de la Encuesta industrial Mensual del INEGI, se estiman distintos modelos con datos de panel y se selecciona el más idóneo con base a pruebas de especificación. Se encuentra que la elasticidad demanda-producto es la más relevante de todas. La elasticidad demanda - salarios es negativa, y sólo es significativa para explicar la demanda de trabajo especializado. La productividad laboral y las exportaciones son significativas y tienen un efecto negativo y positivo respectivamente, sobre la demanda de trabajo total, especializado y no especializado.

Códigos JEL: J23, J24, J31

Palabras clave: Empleo; Industria manufacturera; Datos de panel.

\footnotetext{
*Autor para correspondencia.

Correo electrónico: rtavares@uabc.edu.mx (R. Tavares Luna)

La revisión por pares es responsabilidad de la Universidad Nacional Autónoma de México.
} 


\begin{abstract}
The purpose of the document is to analyze the demand for employment in the manufacturing industry in Mexico, during the period from 2007 to 2015, considering 19 subsectors of the manufacturing industry. The effect that economic performance variables have as the gross domestic product, as well as wages, is analyzed. Labor productivity and manufacturing exports are also considered as explanatory variables. With information from the INEGI Monthly Industrial Survey, different models with panel data are estimated and the most suitable one is selected based on specification tests. It is found that the demand-product elasticity is the most relevant of all. The demand elasticity - wages is negative, and it is only significant to explain the demand for specialized work. Labor productivity and exports are significant and have a negative and positive effect, respectively, on the demand for total, specialized and non-specialized work.
\end{abstract}

JEL Codes: J23, J24, J31

Keywords: Employment; Manufacturing; Panel data.

\title{
Introducción
}

Actualmente en la esfera nacional persisten una serie de fenómenos que dan cuenta del desempeño macroeconómico y sectorial de la economía como la inflación, la informalidad laboral, el lento crecimiento y la desigualdad en los ingresos, todos con implicaciones en la esfera productiva y social tanto a escala nacional como regional y local. Sin embargo, también es conveniente destacar que en el ámbito del mercado laboral se presentan retos importantes, pues existe la imperiosa necesidad de que el aparato productivo despliegue una mayor capacidad para generar empleos formales y así, corresponder a la demanda de empleo que exhibe la población económicamente activa, (PEA). Desde esta óptica, también es importante repensar en políticas públicas que ayuden a detonar el empleo desde la estructura empresarial y sectorial y con ello alentar las condiciones de bienestar social, minimizando los niveles de pobreza que prevalecen en la economía mexicana.

En este marco de reflexión cabe apuntar que las cifras de personal ocupado que reporta la Encuesta Industrial Mensual del Instituto Nacional de Estadística y Geografía (INEGI), indican que la mayor cantidad de la fuerza de trabajo labora en el sector terciario, mientras que el sector secundario y primario se ubican en una posición inferior respectivamente. Tomando en consideración lo anterior, se considera apremiante estimar una función de demanda de empleo relacionada con el sector manufacturero de la economía mexicana durante el periodo 2007-2015. La idea de contemplar un nivel de desagregación por subsectores es con el interés de estudiar las asimetrías que se manifiestan dentro del sector manufacturero en materia de empleo, sueldos y salarios, pero además con la expectativa de integrar una base de datos que permita analizar las relaciones analíticas entre las variables, capturando la parte temporal y transversal del objeto de estudio.

En estudios como el del Banco Mundial (2012) se señala que el análisis del empleo es fundamental en virtud de que es un indicador que incide directamente en el desarrollo económico y social de un país, ya que a través de un ingreso salarial se puede garantizar cierto nivel de subsistencia y calidad de vida, lo que significa atemperar el grado de pobreza en los hogares. 
En consecuencia, lo que se busca es indagar el comportamiento de la demanda de empleo en la industria manufacturera; un sector que a lo largo de los años ha sido fundamental y articulado a los procesos de crecimiento económico y apertura comercial. Si bien se puede afirmar que la economía nacional registra un proceso de terciarización respecto al empleo, también es verdad que el sector secundario no es el más contraído en términos de personal ocupado, pues registra una tasa de participación en el total de la economía superior a la que presenta el sector primario. En el caso específico del comercio y los servicios, así como de la industria manufacturera, se precisa que previo a la crisis de 2008, la participación del personal ocupado de la manufactura era superior a la que refleja después de dicho año, mientras que los servicios y comercio, ya venían reflejando una trayectoria ascendente. No obstante, se advierte de acuerdo con información de la Encuesta Industrial Mensual, que el empleo en la manufactura sigue un proceso de recuperación después del episodio de crisis, lo que significa que viene teniendo un impacto favorable en el mercado laboral y revirtiendo su senda de crecimiento. De acuerdo con cifras de las cuentas nacionales del INEGI, el sector secundario se integra por la minería, por la generación, transmisión, distribución de energía eléctrica, suministro de agua y de gas por ductos para consumo final, por la construcción y la industria manufacturera, siendo ésta última la que mayor peso tiene en el sector secundario. La manufactura en particular, registró una variación de $7.1 \%$ en el cuarto trimestre de 1995 y en el primer trimestre de 2009 de $-10.6 \%$. No obstante a ello, desde el segundo trimestre de 2009 hasta la fecha reporta una trayectoria de recuperación con una tendencia similar a la que se suscita después de la crisis de 1994 .

En este contexto, el objetivo de la presente investigación es estimar una función de demanda de empleo para la industria manufacturera, a fin de identificar aquellos factores que pueden ser relevantes para detonar los niveles de ocupación en un entorno de lento crecimiento y profundas desigualdades sociales. Si bien existe una vasta literatura asociada al tópico, también es verdad que es un tema medular en el análisis económico, que requiere seguir estudiándose. El trabajo empírico analiza por separado el segmento de los obreros y los empleados para los cuales la encuesta industrial, proporciona información en una frecuencia trimestral. Lo que se busca es evaluar la misma función econométrica en ambos casos e identificar posibles efectos diferenciados, considerando a ambos segmentos como fuerza de trabajo no especializada y especializada respectivamente. Los hallazgos permitirán reflexionar en torno al tópico de estudio y esbozar elementos que puedan contribuir en el diseño de políticas y/o programas en el ámbito del desarrollo económico sectorial. Lo que subyace en el trabajo empírico es el contraste de la hipótesis de trabajo, que establece que la demanda de empleo en el sector manufacturero, responde esencialmente a la dinámica del producto y el sector externo y no tanto a los costos salariales como postula la teoría convencional.

El trabajo se estructura en tres secciones. En la primera, se ofrece un panorama general del desempeño de la industria manufacturera a escala agregada y por subsectores, con el propósito de identificar características distintivas entre las actividades económicas que la integran. El bosquejo se centra en indicadores como el personal ocupado, la participación de la manufactura y sus subsectores en el producto interno bruto total, los sueldos, salarios y remuneraciones. En esta sección se procura comprender mejor los sectores que en lo sucesivo se analizan empíricamente. En la segunda sección se exponen los argumentos teóricos que le dan sentido a la hipótesis de trabajo y se efectúa una revisión de literatura empírica que aborda de manera reflexiva el tópico de la demanda de empleo, procurando así, contextualizar los hallazgos encontrados. En la tercera sección se presenta la metodología econométrica de 
panel de datos, destacando su relevancia dada la naturaleza de la información y justificando su instrumentación, así mismo, se discuten los principales hallazgos a la luz de la hipótesis de trabajo. Finalmente se plantean las conclusiones derivadas del trabajo empírico.

\section{Desempeño de indicadores laborales}

En esta sección se expone el comportamiento de un conjunto de indicadores del mercado laboral como el personal ocupado, sueldos, salarios y remuneraciones con el interés tener un acercamiento al desempeño de la industria manufacturera y sus subsectores, considerando que son variables relevantes en la dinámica de dicho mercado. Si bien en el análisis empírico se involucran otras variables, en esta sección se omiten por razones de espacio y se centra la atención en las ya referidas. De acuerdo con información disponible del Instituto Nacional de Estadística y Geografía (INEGI), durante el cuarto trimestre del 2015 el $61.33 \%$ de Personal Ocupado (PO) estaba ubicado en el sector terciario, mientras que el $24.71 \%$ y el $13.37 \%$ en el sector secundario y primario respectivamente. Esta distribución por sectores de actividad muestra que en materia de empleo, la economía nacional está prácticamente terciarizada, notándose una clara asimetría entre ellos. Al respecto, Loria (2010) plantea que ha habido un proceso de destrucción de empleo. Un hecho que sin duda implica retos en materia de política económica y de capacidad para generar más puestos de trabajo.

En la figura 1 se puede observar con más detalle su evolución en el tiempo pero también en términos comparativos. Por ejemplo, desde el primer trimestre del 2005 al cuarto trimestre del 2015 , alrededor del $60 \%$ del personal ocupado se ubica en el sector terciario y menos del $30 \%$ en el sector secundario. Por su parte, el sector primario es el más contraído en términos de su capacidad para generar empleo y es visible la brecha tan marcada entre los tres sectores. En este contexto, Ruiz (2005) afirma que en México se esperaba que el proceso de emigración laboral del sector primario hacia los centros urbanos, sería absorbida por las industrias, desencadenando un crecimiento en el nivel de ocupación laboral. Se advierte que probablemente el uso de tecnología ahorradora de mano de obra, explique el fenómeno de estudio.

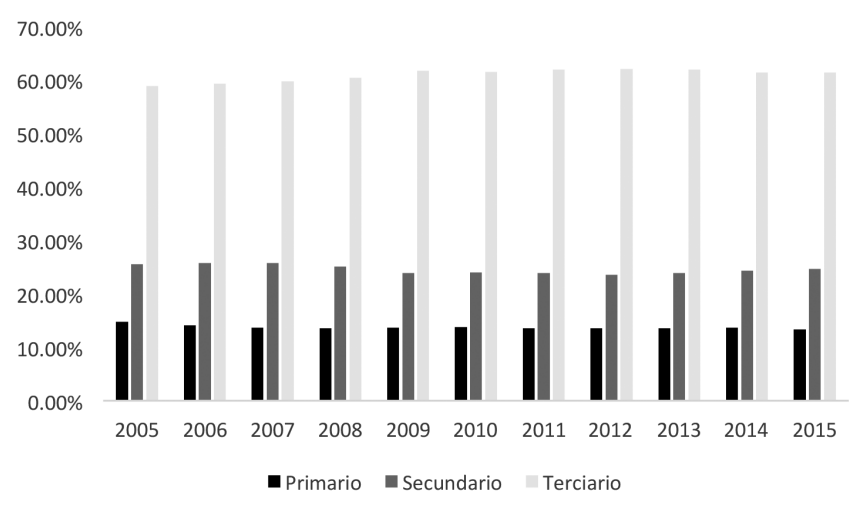

Fuente: Elaboración propia con datos de INEGI. 
En este contexto de desempeño de los grandes sectores de la economía nacional, Ros (2005) prueba empíricamente para un grupo de países latinoamericanos que el abatimiento del desempleo ha mejorado en aquellos casos en donde han tenido un buen desempeño las exportaciones y el empleo manufacturero. Por su parte, Moreno (2016) argumenta que tener una industria manufacturera con potencial exportador y capacidad de generación de empleo, es apremiante para lograr un desarrollo económico sostenido y sustentable. En esta vertiente, es deseable implementar políticas industriales que vayan orientadas a estimular el desarrollo de la industria manufacturera y el valor agregado. Si bien Ruiz (2005) asocia la pérdida de dinamismo del mercado laboral a una baja inversión y al uso de tecnologías ahorradoras de mano de obra, también hay otros autores como Peralta (2010), que sostienen argumentos similares con respecto a la explicación de un mercado laboral contraído. En un análisis efectuado por ramas económicas, Dussel (2003) señala que desde 1988 el país se ha especializado en un conjunto de actividades de orientación exportadora que son intensivas en capital, lo que ha conllevado a generar un reducido proceso de generación de empleo. Se señala que los sectores no transables han sido las principales actividades que han generado empleo. En esta discusión, Samaniego (2014) señala que en los primeros diez años del siglo XXI, ha habido una destrucción de empleo en términos netos. Se precisa que en el año 2009 el nivel de empleo formal llegó a su nivel más bajo comparado con años previos.

Con el interés de analizar más detalladamente la dinámica del PO en la industria de la manufactura, se realiza un análisis por subsector con el propósito de identificar contrastes entre los mismos. De acuerdo con información de la Encuesta Industrial Mensual del INEGI, el sector manufacturero se divide en 21 subsectores: 311 Industria alimentaria, 312 Industria de las bebidas y del tabaco, 313 Fabricación de insumos textiles y acabado de textiles, 314 Fabricación de productos textiles, excepto prendas de vestir, 315 Fabricación de prendas de vestir, 316 Curtido y acabado de cuero y piel, y fabricación de productos de cuero, piel y materiales sucedáneos, 321 Industria de la madera, 322 Industria del papel, 323 Impresión e industrias conexas, 324 Fabricación de productos y derivados del petróleo y del carbón, 325 Industria química, 326 Industria del plástico y del hule, 327 Fabricación de productos a base de minerales no metálicos, 331 Industrias metálicas básicas, 332 Fabricación de productos metálicos, 333 Fabricación de maquinaria y equipo, 334 Fabricación de equipo de computación, comunicación, medición y de otros equipos, componentes y accesorios electrónicos, 335 Fabricación de accesorios, aparatos eléctricos y equipo de generación de energía eléctrica, 336 Fabricación de equipo de transporte, 337 Fabricación de muebles, colchones y persianas y 339 Otras industrias manufactureras, (INEGI, 2013).

Los datos reportados en la tabla número 1 muestran el porcentaje de PO por subsector con relación al total de la industria manufacturera, las cifras dan cuenta de la distribución del empleo generado en forma desagregada y permiten identificar sectores con mayor y menor potencial para absorber fuerza de trabajo que forma parte de la población económicamente activa, PEA. Los subsectores que reportan la mayor cantidad de PO específicamente en el año 2015, fueron el 336 (Fabricación de equipo de transporte) con 22.31\% y 311 (Industria alimentaria) con $18.77 \%$, sumando una participación de $41.08 \%$ ambos. Después de ellos, le sigue el 334 (Fabricación de equipo de computación, comunicación, medición y de otros equipos, componentes y accesorios electrónicos) con un $7.46 \%$ y todos los demás con proporciones muy pequeñas con relación al total. En contraste, los subsectores con menor proporción en el mismo año fueron el 321 (Industria de la madera) y 314 (Fabricación de productos textiles, excepto 
prendas de vestir) con $0.41 \%$ y $0.57 \%$ respectivamente.

Si se analiza la información a lo largo del tiempo, se identifica que los subsectores más destacados en materia de empleo, son el 326, 331, 333, 336 y 339, ya que son los que presentan mayor proporción de PO en el 2015 pero con respecto al 2007. Dentro de este grupo, resalta el subsector 336 (Fabricación de equipo de transporte), que es el que registra el mayor incremento en todo el periodo. Se observa que el 315 (Fabricación de prendas de vestir) es el que exhibe una mayor disminución entre ambos años.

\begin{tabular}{cccccccccc} 
Tabla 1 \\
Proporción del personal ocupado por subsector en el total de la manufactura $2007-2015$ \\
\hline Periodo & 2007 & 2008 & 2009 & 2010 & 2011 & 2012 & 2013 & 2014 & 2015 \\
\hline 311 & 18.95 & 19.49 & 21.50 & 20.64 & 20.02 & 19.71 & 19.37 & 19.01 & 18.77 \\
312 & 4.18 & 4.22 & 4.65 & 4.27 & 4.05 & 3.90 & 3.68 & 3.55 & 3.53 \\
313 & 2.20 & 2.04 & 2.04 & 1.96 & 1.87 & 1.80 & 1.76 & 1.67 & 1.63 \\
314 & 0.71 & 0.67 & 0.66 & 0.60 & 0.57 & 0.57 & 0.55 & 0.57 & 0.57 \\
315 & 6.04 & 5.75 & 5.72 & 5.26 & 4.91 & 4.59 & 4.56 & 4.36 & 4.19 \\
316 & 2.01 & 1.95 & 1.99 & 2.03 & 2.01 & 2.03 & 2.00 & 1.90 & 1.86 \\
321 & 0.57 & 0.56 & 0.56 & 0.51 & 0.48 & 0.47 & 0.45 & 0.43 & 0.41 \\
322 & 2.09 & 2.16 & 2.29 & 2.28 & 2.21 & 2.15 & 2.13 & 2.08 & 2.03 \\
323 & 1.00 & 1.02 & 1.05 & 1.04 & 1.04 & 0.97 & 0.91 & 0.87 & 0.85 \\
324 & 0.86 & 0.90 & 0.95 & 0.94 & 0.93 & 0.91 & 0.90 & 0.89 & 0.83 \\
325 & 4.90 & 4.93 & 5.28 & 5.11 & 5.02 & 5.02 & 4.78 & 4.60 & 4.35 \\
326 & 5.31 & 5.38 & 5.27 & 5.56 & 5.60 & 5.66 & 5.64 & 5.55 & 5.59 \\
327 & 3.11 & 3.12 & 3.07 & 3.02 & 3.00 & 2.96 & 2.90 & 2.85 & 2.81 \\
331 & 2.28 & 2.35 & 2.38 & 2.37 & 2.45 & 2.50 & 2.51 & 2.50 & 2.47 \\
332 & 7.12 & 7.60 & 7.61 & 7.46 & 7.16 & 6.79 & 6.62 & 6.64 & 6.62 \\
333 & 2.58 & 2.64 & 2.46 & 2.66 & 2.83 & 2.86 & 2.93 & 2.94 & 2.99 \\
334 & 8.90 & 8.62 & 7.91 & 8.24 & 7.94 & 7.59 & 7.61 & 7.34 & 7.46 \\
335 & 5.59 & 5.39 & 5.11 & 5.23 & 5.05 & 4.81 & 4.70 & 4.84 & 4.87 \\
336 & 15.93 & 15.46 & 13.69 & 14.93 & 17.02 & 18.88 & 20.22 & 21.57 & 22.31 \\
337 & 1.69 & 1.67 & 1.59 & 1.55 & 1.43 & 1.40 & 1.39 & 1.37 & 1.39 \\
339 & 3.98 & 4.08 & 4.21 & 4.35 & 4.41 & 4.43 & 4.37 & 4.46 & 4.49 \\
\hline Total & 100 & 100 & 100 & 100 & 100 & 100 & 100 & 100 & 100 \\
\hline
\end{tabular}

Fuente: Elaboración propia con datos de INEGI.

Una variable que está muy vinculada con la evolución del mercado laboral es el producto del trabajo. De acuerdo con McConell y Macpherson (2003), la demanda de trabajo es una demanda derivada en razón de que responde al nivel de producto o generación de servicios. En este sentido, se establece que existe una relación positiva entre las variaciones del producto y el nivel de empleo de una economía. El crecimiento económico genera efectos positivos en toda la población, provocando así, una mayor generación de empleos (Isaza y Meza, 2004). Por lo tanto, se espera que un incremento en el producto provoque un aumento en la cantidad demandada de trabajadores, ya que para producir mayores unidades de producción se necesitaría una mayor cuantía del insumo de trabajo, sobre todo en aquellos sectores menos especializados. En este marco de discusión, resulta importante observar la evolución del PIB en el sector manufacturero a nivel de subsector (véase Tabla 2). Los datos permiten ver cuáles subsectores han disminuido su participación en el PIB total de la industria manufacturera y que otros han tenido un mayor impacto. Destaca el caso del subsector 311(Industria alimentaria) al representar la mayor cantidad de producto en todo el periodo y aunque no es el que genera más empleo, sí ha sido uno de los subsectores que ha venido sobresaliendo. Resulta interesante 
notar que en los años donde otros subsectores fueron afectados por la crisis, este mantuvo un ritmo de crecimiento. Por ejemplo, en 2009 su proporción con respecto al PIB total, significó el 24.23\%. También destaca el subsector 336 (Fabricación de equipo de transporte) que se caracteriza por ser el que más empleo genera. Igualmente se identifica que el subsector 325 (Industria química), ha disminuido su representatividad en el PIB total en el transcurso del periodo de estudio.

Tabla 2

Proporción en el PIB de la industria manufacturera miles de pesos de 2008

\begin{tabular}{ccccccccccc}
\hline Periodo & 2007 & 2008 & 2009 & 2010 & 2011 & 2012 & 2013 & 2014 & 2015 & Promedio \\
\hline 311 & 21.80 & 22.27 & 24.23 & 22.70 & 22.17 & 21.84 & 21.82 & 21.10 & 20.84 & 22.09 \\
312 & 4.94 & 5.11 & 5.60 & 5.18 & 5.19 & 5.11 & 5.03 & 5.06 & 5.22 & 5.16 \\
313 & 0.87 & 0.82 & 0.83 & 0.85 & 0.77 & 0.77 & 0.74 & 0.69 & 0.68 & 0.78 \\
314 & 0.68 & 0.64 & 0.64 & 0.60 & 0.56 & 0.54 & 0.55 & 0.56 & 0.60 & 0.60 \\
315 & 2.69 & 2.76 & 2.78 & 2.68 & 2.57 & 2.46 & 2.51 & 2.34 & 2.44 & 2.58 \\
316 & 0.89 & 0.85 & 0.89 & 0.88 & 0.84 & 0.83 & 0.82 & 0.77 & 0.77 & 0.84 \\
321 & 1.02 & 0.95 & 0.99 & 0.96 & 0.96 & 1.04 & 1.01 & 0.98 & 0.98 & 0.99 \\
322 & 1.94 & 2.01 & 2.18 & 2.08 & 1.97 & 1.99 & 2.01 & 1.99 & 2.00 & 2.02 \\
323 & 0.77 & 0.81 & 0.83 & 0.84 & 0.83 & 0.77 & 0.71 & 0.67 & 0.65 & 0.76 \\
324 & 4.25 & 4.28 & 4.69 & 4.01 & 3.69 & 3.59 & 3.67 & 3.37 & 3.03 & 3.84 \\
325 & 13.43 & 13.25 & 14.01 & 12.86 & 12.28 & 11.76 & 11.73 & 11.19 & 10.77 & 12.37 \\
326 & 2.79 & 2.72 & 2.68 & 2.80 & 2.86 & 2.99 & 2.90 & 2.94 & 2.99 & 2.85 \\
327 & 5.77 & 5.61 & 5.54 & 5.34 & 5.30 & 5.21 & 4.99 & 4.90 & 5.01 & 5.30 \\
331 & 7.24 & 7.24 & 6.60 & 6.83 & 6.81 & 6.79 & 6.74 & 7.05 & 6.59 & 6.88 \\
332 & 3.47 & 3.48 & 3.26 & 3.27 & 3.35 & 3.34 & 3.19 & 3.26 & 3.35 & 3.33 \\
333 & 3.22 & 3.25 & 2.84 & 3.85 & 4.17 & 4.23 & 4.22 & 4.04 & 3.90 & 3.75 \\
334 & 4.80 & 4.43 & 4.34 & 4.15 & 4.23 & 4.08 & 4.19 & 4.46 & 4.64 & 4.37 \\
335 & 3.30 & 3.24 & 3.16 & 3.20 & 3.03 & 2.96 & 2.87 & 2.99 & 3.08 & 3.09 \\
336 & 12.54 & 12.68 & 10.18 & 13.34 & 14.87 & 16.26 & 16.99 & 18.32 & 19.05 & 14.91 \\
337 & 1.39 & 1.35 & 1.37 & 1.36 & 1.31 & 1.30 & 1.21 & 1.14 & 1.19 & 1.29 \\
339 & 2.20 & 2.27 & 2.36 & 2.22 & 2.23 & 2.15 & 2.13 & 2.17 & 2.20 & 2.21 \\
\hline Total & 100 & 100 & 100 & 100 & 100 & 100 & 100 & 100 & 100 & 100 \\
\hline F & & & & &
\end{tabular}

Fuente: Elaboración propia con datos de INEGI.

Otras variables de importancia y estrechamente ligadas al mercado laboral son los sueldos, salarios y remuneraciones por subsector. En la Tabla número 3 se reporta el promedio de dichas variables por trabajador y subsector para el periodo que va de del año 2007 hasta $2015^{1}$. Lo primero que se observa es justamente la diferencia entre sueldos y salarios, la cual es muy marcada prácticamente en todos los subsectores. Es importante considerar que en el caso de los sueldos, fundamentalmente se está hablando de fuerza de trabajo especializada mientras que, en el caso de los salarios a obreros, personal ocupado directamente involucrado en las tareas de producción y cuyo nivel de especialización y acervo de capital humano es en promedio inferior. En este sentido, lo que trata de ilustrar la información de la Tabla 3, son las diferencias de ingreso que existen en dos segmentos diferentes del mercado laboral de la industria manufacturera.

\footnotetext{
${ }^{1}$ Según la EMIM (2013), los salarios son los pagos que realizó el establecimiento para retribuir el trabajo ordinario y extraordinario de los obreros, antes de cualquier deducción retenida por los empleadores, mientras que los sueldos son los pagos que realizó el establecimiento para retribuir el trabajo ordinario y extraordinario de los empleados. Las remuneraciones son los pagos y aportaciones antes de cualquier deducción, para retribuir el trabajo del personal, ya sea que este pago se calcule sobre la base de una jornada de trabajo o por la cantidad de trabajo desarrollado (destajo); o mediante un salario base que se complemente con comisiones por venta u otras actividades. Tanto los sueldos, salarios y remuneraciones se registran en miles de pesos corrientes.
} 
Los datos indican que el subsector 324 (Fabricación de productos derivados del petróleo y del carbón) registra niveles salariales mayores que los demás, incluso el salario por trabajador, supera el sueldo por trabajador en varios subsectores con excepción de los subsectores 324 (Fabricación de productos derivados del petróleo y del carbón), 325 (Industria química), 333(Fabricación de maquinaria y equipo), 334 (Fabricación de equipo de computación, comunicación, medición y de otros equipos, componentes y accesorios electrónicos), 335 (335 Fabricación de accesorios, aparatos eléctricos y equipo de generación de energía eléctrica) y 339 (Otras industrias manufactureras). Por otra parte, se identifica que los subsectores con más bajos salarios son el 314 (Fabricación de productos textiles, excepto prendas de vestir) y 315 (Fabricación de prendas de vestir) que además tienen menor cantidad de PO en el periodo de análisis. En lo que concierne a las remuneraciones, se observa que en el subsector 324 es en donde se registran las remuneraciones por trabajador más elevadas ligado nuevamente a la fabricación de productos derivados del petróleo y el cambó, mientras que el subsector que registra el nivel más bajo en el indicador es el 315, relacionado con las prendas de vestir.

Tabla 3

Promedio de salarios, sueldos y remuneraciones por trabajador y subsector durante el periodo 2007-2015

\begin{tabular}{|c|c|c|c|}
\hline Subsector & Salarios & Sueldos & Remuneraciones \\
\hline 311 Industria alimentaria & 4.03 & 8.50 & 6.57 \\
\hline 312 Industria de las bebidas y del tabaco & 4.94 & 9.35 & 8.65 \\
\hline 313 Fabricación de insumos textiles y acabado de textiles & 4.63 & 9.77 & 7.06 \\
\hline 314 Fabricación de productos textiles, excepto prendas de vestir & 3.85 & 8.34 & 6.10 \\
\hline 315 Fabricación de prendas de vestir & 3.70 & 8.21 & 5.29 \\
\hline $\begin{array}{l}316 \text { Curtido y acabado de cuero y piel, y fabricación de } \\
\text { productos de cuero, piel y materiales sucedáneos }\end{array}$ & 4.20 & 8.19 & 6.14 \\
\hline 321 Industria de la madera & 4.07 & 7.43 & 6.03 \\
\hline 322 Industria del papel & 5.80 & 14.46 & 10.66 \\
\hline 323 Impresión e industrias conexas & 5.54 & 10.00 & 8.52 \\
\hline $\begin{array}{l}324 \text { Fabricación de productos derivados del petróleo } \\
\text { y del carbón }\end{array}$ & 17.18 & 33.06 & 32.90 \\
\hline 325 Industria química & 10.03 & 18.03 & 17.41 \\
\hline 326 Industria del plástico y del hule & 4.42 & 11.37 & 7.69 \\
\hline 327 Fabricación de productos a base de minerales no metálicos & 5.44 & 15.52 & 9.92 \\
\hline 331 Industrias metálicas básicas & 7.15 & 16.11 & 12.88 \\
\hline 332 Fabricación de productos metálicos & 4.78 & 12.31 & 7.86 \\
\hline 333 Fabricación de maquinaria y equipo & 6.10 & 18.33 & 11.90 \\
\hline $\begin{array}{l}334 \text { Fabricación de equipo de computación, comunicación, } \\
\text { medición y de otros equipos, componentes y accesorios } \\
\text { electrónicos }\end{array}$ & 5.27 & 18.16 & 9.96 \\
\hline 335 Fabricación de accesorios, aparatos eléctricos y equipo & 4.92 & 18.31 & 9.50 \\
\hline de generación de energía eléctrica & 5.10 & 16.62 & 10.05 \\
\hline \multicolumn{4}{|l|}{336 Fabricación de equipo de transporte } \\
\hline 337 Fabricación de muebles, colchones y persianas & 4.91 & 12.95 & 7.83 \\
\hline 339 Otras industrias manufactureras & 5.38 & 18.31 & 9.63 \\
\hline
\end{tabular}

Fuente: Elaboración propia con datos de EMIM (2007-2015).

\section{Revisión de literatura: una perspectiva teórica y empírica}

El objetivo de esta sección va en dos direcciones, primero efectuar una presentación de la teoría que sustenta el trabajo de investigación y en lo sucesivo, una revisión de literatura empírica relacionada con el estudio de la demanda de empleo. Se analiza la literatura relacionada con la experiencia internacional y con el caso de la economía mexicana haciendo énfasis en 
sus principales hallazgos. Los factores que se toman en cuenta en el trabajo de estimación, se enmarcan en dos vertientes teóricas que permiten establecer el vínculo entre la demanda de empleo y la dinámica de crecimiento económico, las remuneraciones, salarios y sueldos. La hipótesis de trabajo que se aborda, postula que la demanda de fuerza de trabajo en la industria manufacturera es más sensible a los cambios registrados en el crecimiento económico que a los movimientos de los salarios. Sin embargo, también se plantea que los cambios en la productividad laboral operan en contra del nivel de empleo de la manufactura, toda vez que genera un efecto de desplazamiento derivado de un sesgo ocasionado posiblemente por el cambio tecnológico, que es más acentuado en el segmento de los obreros.

El planteamiento neoclásico sostiene que en el mercado laboral opera un mecanismo de ajuste entre la demanda y oferta de trabajo toda vez que los salarios son flexibles y no enfrentan rigideces. Esta condición es lo que permite que sea factible alcanzar un estado de equilibrio y que se converja a un nivel de pleno empleo. Además, se plantea que el mercado es competitivo, lo que significa que los salarios se ajustan de forma natural sin haber acciones de regulación por parte del Estado. Desde esta perspectiva, se estima que prácticamente no hay desempleo involuntario y que únicamente podrá haber desocupación voluntaria y de carácter transitoria. Por tanto, es un enfoque que supone que no hay factores de rigidez que puedan impedir el libre ajuste de los salarios. Se argumenta que en la medida que los salarios desciendan habrá una mayor demanda de fuerza de trabajo. En Martínez et al. (2001) se apunta que al intervenir de alguna manera agentes externos no se permite la libre competencia en el mercado laboral y se pierde eficiencia en el mismo. Por tanto, la variable clave que estaría explicando la dinámica del empleo sería el salario, razón por lo cual se considera como un factor que explica la demanda de empleo.

Por otra parte, Argoti (2011) explica que la teoría keynesiana surge en el contexto de la crisis económica de 1929, periodo en el que se registraron elevadas tasas de desempleo que no se explicaron por los ajustes en los salarios, sino por un nivel de insuficiencia de demanda que no fue capaz de detonar un mayor nivel de ocupación. En este enfoque teórico se sostiene que en realidad los salarios son rígidos y que las condiciones de competencia perfecta no se cumplen, además se indica que la falta de flexibilidad en los salarios no garantiza el equilibrio automático del mercado laboral, produciéndose una situación en donde prevalece el desempleo involuntario. En este sentido, se afirma que la intervención del Estado en la economía, la fijación de un salario mínimo o el rol de los sindicatos en los procesos de negociación colectiva, son factores de rigidez que explican que el mercado laboral no se autorregule automáticamente garantizando una condición de pleno empleo. Desde el ámbito de la economía normativa, la explicación keynesiana respecto al desempleo, sostiene que se podrá reducir en la medida que el Estado juegue un rol preponderante a través de una política de gasto público que incida en la demanda efectiva y con ello, en el nivel de actividad económica. Por consiguiente, la variable relevante que explicaría la demanda de empleo sería un indicador de demanda o de actividad económica, habiendo una relación positiva entre nivel de empleo y crecimiento del producto nacional.

Tomando como referencia el objeto de estudio y el esbozo teórico previo, se procede a efectuar una revisión de literatura especializada en el ámbito de interés. Aunque el empleo puede tener diferentes explicaciones y características de un país a otro y en periodos distintos, es importante destacar algunos hallazgos empíricos. Por ejemplo, en Hamermesh (1993) se afirma que la elasticidad empleo-salario oscila en el largo plazo dentro de un rango de -0.15 a - 0.75 ; considerando el valor de -0.3 como un buen resultado. En una revisión más actual de la demanda de trabajo para siete países de América Latina y el Caribe incluyendo a México, 
el propio Hamermesh (2003), retoma algunos trabajos que se han efectuado sobre funciones de demanda de empleo, en donde se contempla el producto y el salario como determinantes fundamentales. En general se observa que las elasticidades empleo-salario son negativas, como se esperaría de acuerdo a la teoría. Un rasgo que se identifica es que la elasticidad es mayor para el caso de trabajadores calificados que no calificados, independientemente de que los datos sean agregados, por establecimiento o por firma.

Para el caso de Argentina, Lanteri (2013) investiga los principales factores que explican el nivel de empleo; en particular el vínculo empleo-salarios reales y la elasticidad empleoproducto de largo plazo. Utilizando datos trimestrales correspondientes al periodo 1994/032011/02, se estima un modelo de corrección de error VEC que le permite estimar los ajustes dinámicos de corto plazo y las relaciones de largo plazo entre las variables. Encuentra que, aunque el crecimiento económico y la reestructuración productiva operan a favor de sectores intensivos en trabajo, no parece ser suficiente para reducir el desempleo.

En el estudio de Bencosme (2008) se hace una estimación de la demanda de trabajo para la República Dominicana para el periodo 1991-2006 utilizando datos de panel. Su objetivo es contrastar si la elasticidad empleo-producto tuvo un cambio en el tiempo; se encuentra que hubo una disminución en las elasticidades empleo-producto a partir del año 2000 en los sectores intensivos en capital. En el caso del salario, se constata que tiene un impacto significativo y negativo en el empleo, sin embargo, su elasticidad es baja en comparación de otros países. Medina et al. (2012) estima un modelo Panel-VAR para analizar las principales variables que inciden en la dinámica de la demanda laboral de la industria manufacturera colombiana para los periodos 1993-2009 y 2000-2009. Se argumenta que los modelos Panel-VAR pueden arrojar mejores resultados que una metodología estándar que puede presentar un posible sesgo por simultaneidad. Se determina que el empleo industrial (obrero), presenta una fuerte persistencia y que la demanda de empleo es sensible a choques sobre la producción de la firma. También se encuentra que la respuesta del empleo obrero a su salario es significativamente mayor a la encontrada para el caso del empleo no obrero.

En el caso de la investigación de Castillo (2006) se estima una función de demanda laboral industrial en el área metropolitana de Cali, Colombia para el periodo 1995-2001; se trabaja con un modelo de efectos fijos de datos de panel para 17 sectores y se obtiene una elasticidad empleo-salario negativa y una elasticidad empleo-producto positiva. También se determina que la generación de empleos está determinada mayormente por el producto que por los salarios y que los subsectores que generan más empleo son los que utilizan mayor tecnología.

Para el caso de Chile, Martínez et al. (2001) indagan sobre posibles cambios estructurales en la demanda de trabajo para el periodo trimestral de 1986:1-2000:4; estiman dos modelos para evaluar una posible disminución en la relación entre empleo y producto. Utilizando la metodología de cointegración basada en modelos de vectores autorregresivos y efectuando pruebas de cambio estructural, se demuestra que la elasticidad empleo-producto no ha disminuido, pero sí existe evidencia de inestabilidad en la demanda ya que se encuentra un cambio estructural referido al año 2000.

En el trabajo de Tangarife (2013), se analizan los factores que inciden en la demanda de trabajo en la industria manufacturera de Colombia para el periodo 2002-2009. A partir de un modelo con datos de panel, se señala que el incremento del PIB no ha llevado a un aumento del empleo de manera proporcional. Se hace especial referencia al factor de productividad que puede ser relevante a la hora de explicar la no correspondencia del empleo con el crecimiento 
económico. En las estimaciones se detecta que el crecimiento del salario tiene un efecto positivo en el aumento de la demanda de trabajo y se agrega que en los últimos años, existe una diferencia en los impactos de la productividad en la demanda de trabajo.

En la misma línea de análisis Roberts y Skoufias (1997), estiman funciones de demanda para el empleo obrero y no obrero de las plantas manufactureras de Colombia utilizando datos de panel. Encuentran elasticidades empleo-producto de 0.89 para el empleo no obreros y de 0.76 para el segmento obrero. La elasticidad empleo-salario es de -0.42 para el empleo no obrero y - 0.65 para el empleo obrero. Los resultados muestran que la elasticidad empleosalario del trabajo no calificado es mayor que la del trabajo calificado. La elasticidad empleoproducto, resulta mayor para el trabajo calificado frente al no calificado. Esto quiere decir que los trabajadores no calificados son más sensibles a cambios en el salario que los calificados. También se muestra que los trabajadores calificados son sensibles a cambios en el producto.

En el caso de México también existen diversos estudios que se han enfocado en estudiar la demanda de trabajo. Lechuga y Varela (2001) estiman una función de empleo manufacturero para el periodo 1990-1998 utilizando datos trimestrales. Se consideran variables explicativas como el PIB del sector, la productividad laboral y la formación bruta de capital fijo como proxy de inversión. Las estimaciones indican que los incrementos en la productividad no determinan incrementos sostenidos en las remuneraciones, pero además se afirma, que conllevan a una lenta dinámica del empleo. También se señala que la inversión tiene un efecto positivo pero inelástico en el comportamiento del empleo. En el trabajo se estima de manera adicional una función de salarios y en ambos ejercicios, se utiliza el método de Mínimos Cuadrados Ordinarios con corrección por autocorrelación. Es importante señalar que en la función de empleo no se utiliza la variable salario y es una estimación con información estrictamente temporal y a nivel agregado.

En el trabajo de Loria y Brito (2005) se demuestra el impacto que tiene la inversión extranjera directa sobre el empleo para seis sectores de la economía mexicana. Se estima una función de empleo manufacturero que está determinada por el empleo rezagado en un periodo, el producto manufacturero, los salarios medios reales, los bienes intermedios y de capital y la formación bruta de capital fijo. En otro trabajo como el de Ríos y Carrillo (2014), se estima una función de demanda para el empleo calificado y no calificado de México con datos anuales de 2005-2009. Se demuestra que en periodos de crisis las empresas conservan el trabajo calificado y tienden a despedir trabajadores no calificados siendo más afectados los sectores de la maquiladora y las industrias tradicionales.

Por su parte, Almonte et. al. (2013) estiman una función de empleo para el estado de México con datos de la industria manufacturera por división de actividad económica para el periodo 1999-2008. Con base a una metodología de datos de panel especifican que el empleo manufacturero está en función del PIB, la productividad y los salarios, sus resultados sugieren que incrementos en la productividad ocasionan disminuciones en el nivel de empleo y que la variable con mayor influencia sobre el empleo es el producto.

En el trabajo desarrollado por Félix y Castro (2015) se estima un modelo dinámico de demanda de trabajo para las industrias integradas a las cadenas de valor internacional. Se utilizan datos de la industria automotriz y mediante un modelo de corrección de error obtienen una elasticidad salario-demanda laboral de 0.54. También estiman la velocidad del ajuste ante cualquier desviación del óptimo de largo plazo y determinan que cualquier desviación se corrige en aproximadamente 21 meses. Los resultados ilustran la dependencia de gran parte del 
empleo manufacturero de México con respecto a los costos laborales, así como a la evolución del mercado mundial.

En el trabajo de Fajnzylber y Maloney (2005) se analiza la demanda de trabajo por tipos de empleo. Se estiman demandas de empleo obrero y no obrero utilizando la metodología de Arellano y Bond que se basa en el Método Generalizado de Momentos, se obtienen elasticidades empleo-producto de acuerdo con la teoría. Se consideran datos de Colombia, Chile y México en la década de los ochenta e inicios de los noventas con el propósito de analizar los cambios registrados en la demanda de trabajo frente a las políticas de liberalización comercial. En el caso de Isaza y Meza (2004), las elasticidades empleo-salario para México les permiten a los autores concluir que mayores niveles de apertura comercial conllevan a cambios importantes en los mercados de trabajo y que el comercio internacional afecta las demandas relativas del empleo calificado y no calificado.

A partir de la revisión previa se puede notar que, en efecto, los resultados varían de acuerdo al caso de estudio y dependiendo de la metodología instrumentada, sin embargo, para el caso de México algunos hallazgos destacan que el efecto del nivel de producto y los salarios van en concordancia con la teoría, sin embargo, se aprecia que la magnitud del efecto varía según el nivel de agregación del estudio. En este sentido, en el presente trabajo, lo que se busca es evaluar el efecto de los salarios, el producto y la productividad en la demanda de empleo, considerando el periodo de 2007-2015. Es importante apuntar que es un trabajo que presenta variantes con respecto al de Lechuga y Varela (2001); la primera es que en esta referencia no se integra la variable de salarios en la función econométrica, en segundo lugar, las estimaciones tienen como base una estructura de datos de series de tiempo y el estudio se centra en el agregado de la industria manufactura. Se considera que estudiar la industria a nivel de subsectores e introducir las variables de salarios, sueldos y remuneraciones pueden conducir a resultados diferentes en cuanto a su magnitud, pero en la misma dirección, una vez que se contempla la heterogeneidad no observable en el modelo de panel. Además, se realizan estimaciones para dos segmentos distintos del mercado laboral, trabajo especializado y no especializado tomando como variables proxy a los obreros y empleaos respectivamente de la Encuesta Industrial Mensual de la manufactura.

\section{Metodología de estimación y resultados}

En esta sección se presenta la metodología econométrica y se utiliza una base de datos integrada con información referente a 19 subsectores de la manufactura en México durante el periodo de 2007-2015. La estimación de un modelo con datos de panel consiste básicamente en seguir a lo largo de un horizonte temporal a las mismas unidades de análisis o de corte transversal (Wooldridge, 2007). De acuerdo con la teoría econométrica, un modelo agrupado con datos en panel se expresa como:

$$
y_{i t}=\alpha+\beta x_{i t}+\mu_{i t}
$$

donde $i$ representa al individuo o a la unidad de estudio, $t$ refiere a la dimensión en el tiempo de la información, a denota un intercepto común, $\beta$ es un vector de $k$ parámetros, $x_{i t}$ es la $i$-esima observación al momento $t$ para las $k$ variables explicativas contempladas y $u_{i t}$ es un término de error aleatorio. La muestra total de las observaciones está dada por $\mathrm{N}$ observaciones 
transversales y T observaciones en el tiempo (Pindyck y Rubinfeld, 2001). La ecuación [1] denota una regresión agrupada con un intercepto a común para toda los elementos $i$. Una segunda posibilidad de estimación es considerar que el intercepto varíe por cada unidad de análisis, lo que implica especificar a $i$. En este caso se tendrían interceptos diferenciales dados por $(a+a i)$. El término a $i$ indica un vector de variables dummy asociadas a cada unidad de las secciones cruzadas.

La estimación previa implica estimar efectos fijos en el tiempo, pero variantes en $i$. Una tercera posibilidad es estimar el mismo modelo [1], pero considerando que el intercepto cambia tanto para cada unidad de estudio $i$ como en el horizonte temporal, en cuyo caso el termino correcto es ait . La implicación es que se pueden ver reducidos los grados de libertad si el número total de observaciones no es muy grande. En cualquiera de los últimos dos casos se habla de un modelo de efectos fijos y el valor de a, representaría el intercepto de la categoría de referencia o base, de tal forma que se tendrían en la regresión $N-1$ variables dummy para evitar el problema de multicolinealiad perfecta. También se puede estimar un modelo de efectos aleatorios partiendo de $y i t=\alpha i+\beta x i t+\mu i t$, es decir, en vez de considerar a $a i$ como efecto fijo, se definiría como una variable aleatoria con un valor medio igual a a y el valor del intercepto para cada unidad de análisis estaría definido como $a i=a+\varepsilon i$ siendo $\varepsilon i$ un término de error aleatorio con media igual a cero y varianza constante (Hsiao, 2003). Tomando en consideración la última ecuación y sustituyendo términos, se tiene:

$$
y_{i t}=\alpha+\beta x_{i t}+\varepsilon_{i}+\mu_{i t}
$$

en donde el error compuesto está definido como vit $=\varepsilon i+\mu i t$. De esta forma la ecuación [2] queda reexpresada de la siguiente forma:

$$
y_{i t}=\alpha+\beta x_{i t}+v_{i t}
$$

El término vit se denomina error aleatorio compuesto y está integrado por el componente $\varepsilon i$ que expresa el error aleatorio de corte transversal y $\mu$ it se interpreta como la combinación del error de la serie de tiempo y del corte transversal. A partir de las especificaciones teóricas previas, se estima una regresión con intercepto común que sirve de base, para en lo subsecuente estimar un modelo de efectos fijos y aleatorios. En el caso específico de un modelo de efectos fijos en el tiempo pero variantes en cada unidad de análisis, los modelos [4], [5], y [6] incluirían ai en vez de $a 0$, y con relación al modelo de efectos aleatorios, el término $a 0$ se sustituiría por $a i=a+\varepsilon i$. Los modelos iniciales serían:

$$
\begin{aligned}
& L 1_{i t}=\alpha_{0}+\beta_{1} Y_{i t}+\beta_{2} W 1_{i t}+\beta_{3} P_{i t}+\beta_{4} E_{i t}+u_{i t} \\
& L 2_{i t}=\alpha_{0}+\beta_{1} Y_{i t}+\beta_{2} W 2_{i t}+\beta_{3} P_{i t}+\beta_{4} E_{i t}+u_{i t} \\
& L 3_{i t}=\alpha_{0}+\beta_{1} Y_{i t}+\beta_{2} W 3_{i t}+\beta_{3} P_{i t}+\beta_{4} E_{i t}+u_{i t}
\end{aligned}
$$


La variable $L 1_{i t}$ denota el personal ocupado total de la industria manufacturera en miles de trabajadores, $Y_{i t}$ es el producto bruto real de la industria de la manufactura a precios de 2008. $P_{i t}$ denota un índice de productividad laboral real a precios de 2008 y $E_{i t}$ las exportaciones de la manufactura. La variable $L 2_{i t}$ y $L 3_{i t}$ son el número de obreros y empleaos respetivamente. $W 1_{i t}$ denota las remuneraciones del personal ocupado, $W 2_{i t}$ expresa los salarios de los obreros y $W 3_{i t}$ los sueldos de los empleados, las tres variables están expresadas a precios constantes de 2008. La información para estas variables se obtuvo de la Encuesta Mensual Industrial de la Manufactura. El producto interno bruto real por subsector se obtuvo del Sistema de Cuentas Nacionales del INEGI, mientras que la productividad laboral se obtuvo de la misma Encuesta Mensual Industrial Manufacturera siguiendo la metodología del INEGI (2012). Una vez definidas las variables del modelo, lo que se busca es encontrar relaciones que vayan en concordancia con la teoría, pero también corroborar la hipótesis de trabajo de que la demanda del empleo es más sensible a los cambios del producto que a los de las remuneraciones, sueldos y salarios. En el caso de la productividad se espera una relación negativa, pues se considera que puede tener implicaciones en una menor demanda de fuerza de trabajo y sobre todo más notoriamente en el segmento de los trabajadores menos calificado como los obreros. Las exportaciones se introducen con el propósito de capturar los efectos que tiene el sector externo de la economía en el mercado laboral. Se precisa que no se están incorporando al análisis las exportaciones netas que son la diferencia de las exportaciones menos las importaciones. En realidad, no se contempla el saldo de la balanza comercial o de la cuenta corriente de la balanza de pagos. Al no considerar las exportaciones netas, se estima que es factible introducirlas en la función de demanda de empleo, sin generar problemas de colinealidad con el producto bruto.

Previo a la estimación y discusión de resultados, se procede a realizar un diagnóstico sobre la posible existencia de colinealidad entre las variables. Los resultados que se reportan en la Tabla 4, corresponden a los coeficientes bivariados de correlación de Pearson, su magnitud y signo sugieren que no hay un problema severo de colinealidad ya que en general los valores son realmente bajos. Las variables $W 1_{i t}, W 2_{i t}$ y $W 3_{i t}$, corresponden a las remuneraciones, salarios y sueldos de los trabajadores en total, obreros y empleados. La correlación entre las exportaciones y el producto, se puede considerar relativamente baja ya que no se aproxima a la unidad.

Tabla 4

Matriz de coeficientes de correlación de Pearson

\begin{tabular}{lllllll}
\hline & $Y_{i t}$ & $W 1_{i t}$ & $W 2_{i t}$ & $W 3_{i t}$ & $P R O D_{i t}$ & $E_{i t} P_{i t}$ \\
\hline$Y_{i t}$ & 1.00 & -0.14 & 0.14 & -0.08 & -0.01 & 0.52 \\
$W 1_{i t}$ & -0.14 & 1.00 & - & - & -0.08 & -0.04 \\
$W 2_{i t}$ & 0.14 & - & 1.00 & - & -0.29 & 0.11 \\
$W 3_{i t}$ & -0.08 & - & - & 1.00 & 0.26 & 0.15 \\
$P R O D_{i t}$ & -0.01 & -0.08 & -0.29 & 0.26 & 1.00 & 0.18 \\
$E X P_{i t}$ & 0.52 & -0.04 & 0.11 & 0.15 & 0.18 & 1.00 \\
\hline
\end{tabular}

Fuente: Elaboración propia con datos de INEGI.

Una vez descartado un problema de multicolinealidad, se procede a realizar un diagnóstico respecto a si las series en nivel tienen o no, un problema de raíz unitaria. En la Tabla 5, se reportan los resultados de la prueba de raíz unitaria de Levine - Lin - Chu ( LLC), para datos de panel. La hipótesis nula estipula que hay raíz unitaria y lo resultados sugieren que en todos los casos se rechaza, debido a que el p-value es menor a 0.05 . En este sentido se concluye que las 
series en nivel son integradas de orden cero, I(0). A partir de ello, no es necesario diferenciarlas ni instrumentar alguna metodología de cointegración para datos de panel, ya que la estimación estándar, permiten hacer un análisis de inferencia estadística confiable. Además, se precisa que para realizar un análisis de cointegración las series deberían ser integradas de orden uno, I (1).

Tabla 5

Prueba de Raíz Unitaria para datos de panel

\begin{tabular}{llll}
\hline & Nivel & \multicolumn{2}{c}{ Levin-Lin-Chu } \\
\hline Notación & Variables & Estadístico & Prob. \\
\hline$L 1_{i t}$ & Personal Ocupado & -8.2847 & 0.0000 \\
$L 2_{i t}$ & Obreros & -9.1587 & 0.0000 \\
$L 3_{i t}$ & Empleados & -6.2570 & 0.0000 \\
$W 1_{i t}$ & Remuneraciones & -4.4103 & 0.0000 \\
$W 2^{i t}$ & Salarios & $-4-9846$ & 0.0000 \\
$W 3_{i t}$ & Sueldos & -6.0176 & 0.0000 \\
$Y_{i t}$ & PIB Manufacturero & -13.488 & 0.0000 \\
$P R O D_{i t}$ & Productividad & -1.8796 & 0.0301 \\
EXP $_{i t}$ & Exportaciones & -4.7562 & 0.0000 \\
\hline
\end{tabular}

Hipótesis nula: raíz unitaria

Newey-West automatic bandwidth selection and Bartlett Kernel

Fuente: Elaboración propia con datos de INEGI.

Una vez determinado lo anterior respecto al orden de integración de las series del modelo, se procede a realizar estimaciones para el total del personal ocupado y en lo sucesivo, para el segmento de los obreros y los empleados. Para cada uno de los tres grupos, se estiman cuatro modelos de panel que son los siguientes: 1) modelo con intercepto común, 2) modelo con efectos fijos en $t$ y variantes en $i \mathbf{3}$ ) modelo con efectos fijos en $i$ pero variantes en $t$ y 4) un modelo con efectos aleatorios (véase Tabla 6). También se ilustran las pruebas correspondientes para elegir el modelo más idóneo. Por ejemplo, se estima la estadística F, para elegir entre un modelo con intercepto común o regresión agrupada y un modelo de efectos fijos. También se realiza la prueba de Hausman, para determinar qué modelo es el más idóneo entre el de efectos fijos y el de efectos aleatorios. Igualmente se reportan los resultados del contraste de Breauch Pagan, para elegir entre un modelo con intercepto común y el modelo de efectos aleatorios. En todas las regresiones de panel se obtienen errores estándar robustos con el propósito de obtener resultados confiables. 
Tabla 6

Resultaos de estimación

\begin{tabular}{|c|c|c|c|c|c|c|c|c|c|c|c|c|}
\hline & \multicolumn{4}{|c|}{$\begin{array}{c}\text { Personal Ocupado Total } \\
\qquad L 1_{i t}\end{array}$} & \multicolumn{4}{|c|}{$\begin{array}{l}\text { Obreros } \\
\qquad 2_{i t}\end{array}$} & \multicolumn{4}{|c|}{$\begin{array}{c}\text { Empleados } \\
\qquad 3_{i t}\end{array}$} \\
\hline & M1 & M2 & M3 & M4 & M1 & $M 2$ & M3 & M4 & M1 & $M 2$ & M3 & M4 \\
\hline \multirow[t]{2}{*}{$\bar{C}$} & 12.52 & 5.521 & 12.36 & 5.459 & 23.15 & 5.216 & 23.22 & 5.322 & -1.017 & 7.457 & -5.466 & 6.777 \\
\hline & 5.43 & 0.928 & 14.57 & 0.660 & 4.123 & 0.852 & 9.331 & 0.765 & 2.771 & 0.558 & 5.939 & 0.642 \\
\hline \multirow[t]{2}{*}{$\overline{Y_{i t}}$} & 0.540 & 0.615 & 0.543 & 0.620 & 0.499 & 0.664 & 0.500 & 0.653 & 0.780 & 0.454 & 0.795 & 0.538 \\
\hline & 0.009 & 0.023 & 0.173 & 0.020 & 0.010 & 0.027 & 0.165 & 0.023 & 0.008 & 0.060 & 0.124 & 0.050 \\
\hline \multirow[t]{2}{*}{$W 1_{i t}$} & -2.35 & -0.075 & -2.526 & -0.086 & & & & & & & & \\
\hline & 1.165 & 0.160 & 2.852 & 0.178 & & & & & & & & \\
\hline \multirow[t]{2}{*}{$W 2_{i t}$} & & & & & -4.278 & -0.199 & -4.359 & -0.224 & & & & \\
\hline & & & & & 0.807 & 0.120 & 1.171 & 0.175 & & & & \\
\hline \multirow[t]{2}{*}{$W 3_{i t}$} & & & & & & & & & -0.408 & -0.487 & 0.265 & -0.504 \\
\hline & & & & & & & & & 0.582 & 0.103 & 1.385 & 0.114 \\
\hline \multirow[t]{2}{*}{$\overline{P R O D_{i t}}$} & -0.032 & -0.447 & 0.169 & -0.454 & -0.501 & -0.467 & -0.438 & -0.467 & 0.435 & -0.373 & 0.711 & -0.423 \\
\hline & 0.071 & 0.060 & 0.659 & 0.063 & 0.192 & 0.066 & 0.612 & 0.070 & 0.072 & 0.066 & 0.668 & 0.071 \\
\hline \multirow[t]{2}{*}{$E X P_{i t}$} & 0.307 & 0.127 & 0.305 & 0.134 & 0.355 & 0.144 & 0.355 & 0.153 & 0.159 & 0.101 & 0.151 & 0.106 \\
\hline & 0.003 & 0.011 & 0.083 & 0.010 & 0.007 & 0.009 & 0.079 & 0.009 & 0.008 & 0.013 & 0.080 & 0.020 \\
\hline $\mathrm{R}^{2}$ ajustado & 0.83 & 0.90 & 0.82 & 0.70 & 0.83 & 0.90 & 0.82 & 0.72 & 0.84 & 0.99 & 0.84 & 0.52 \\
\hline \multicolumn{5}{|c|}{ Test $F=655.8 \quad$ prob. 0.0000} & \multicolumn{4}{|c|}{ Test $\mathrm{F}=655.5$} & \multicolumn{4}{|c|}{ Test $\mathrm{F}=422.77 \quad$ prob. } \\
\hline \multicolumn{5}{|c|}{ Ho: $\beta_{0 \mathrm{i}}=\beta_{0}$ (intercepto común) } & \multicolumn{4}{|c|}{ Ho: $\beta_{0 \mathrm{i}}=\beta_{0}$ (intercepto común) } & \multicolumn{4}{|l|}{0.0000} \\
\hline \multicolumn{5}{|c|}{ Test $\mathrm{F}=0.494$} & \multirow{2}{*}{\multicolumn{4}{|c|}{$\begin{array}{l}\text { Test } F=0.248 \quad \text { prob. } 0.980 \\
\text { Ho: } \beta_{0 t}=\beta_{0} \text { (intercepto común) }\end{array}$}} & \multirow{3}{*}{\multicolumn{4}{|c|}{$\begin{array}{l}\text { Ho: } \beta_{0 \mathrm{i}}=\beta_{0} \text { (intercepto común) } \\
\text { Test } F=1.058 \quad \text { prob. } 0.395 \\
\text { Ho: } \beta_{0 \mathrm{t}}=\beta_{0} \text { (intercepto común) }\end{array}$}} \\
\hline \multirow{2}{*}{\multicolumn{5}{|c|}{ Ho: $\beta_{0 \mathrm{t}}=\beta_{0}$ (intercepto común) }} & & & & & & & & \\
\hline & & & & & \multicolumn{4}{|c|}{ 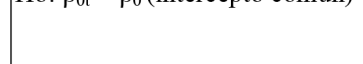 } & & & & \\
\hline \multicolumn{5}{|c|}{ Test de Hausman, Chi-Sq $=6.85$ prob. } & \multirow{2}{*}{\multicolumn{4}{|c|}{$\begin{array}{l}\text { Test de Hausman, Chi-Sq }= \\
12.80 \text { prob. } 0.012 \\
\text { Ho: } \varepsilon_{\mathrm{i}} \text { no están correlacionados } \\
\text { con } \mathrm{X}_{\mathrm{it}}\end{array}$}} & \multirow{2}{*}{\multicolumn{4}{|c|}{$\begin{array}{l}\text { Test de Hausman, Chi-Sq }= \\
13.87 \text { prob. } 0.007 \\
\text { Ho: } \varepsilon_{\mathrm{i}} \text { no están correlacionados } \\
\text { con } \mathrm{X}_{\mathrm{it}}\end{array}$}} \\
\hline \multicolumn{5}{|c|}{ Ho: $\varepsilon_{\mathrm{i}}$ no están correlacionados con $\mathrm{X}_{\mathrm{it}}$} & & & & & & & & \\
\hline Test Breu & $\mathrm{ch}-\mathrm{Pa}$ & $\begin{array}{l}\operatorname{gan}, \mathrm{LM} \\
0.000\end{array}$ & $=618.6$ & 7 prob. & \multirow{2}{*}{\multicolumn{4}{|c|}{$\begin{array}{l}\text { Test Breuch }- \text { Pagan, } L M= \\
2.826 \text { prob. } 0.000 \\
\text { Ho: } \sigma_{\varepsilon i}{ }^{2}=0 \text {, efectos aleatorios } \\
\text { igual a cero }\end{array}$}} & \multirow{2}{*}{\multicolumn{4}{|c|}{$\begin{array}{l}\text { Test Breuch - Pagan, LM= } \\
587.24 \text { prob. } 0.000 \\
\text { Ho: } \sigma_{\varepsilon i}{ }^{2}=0 \text {, efectos aleatorios } \\
\text { igual a cero }\end{array}$}} \\
\hline Ho: $\sigma_{\varepsilon i}^{2}=($ & , efecto & s aleato & rios igua & 1 a cero & & & & & & & & \\
\hline & Elecció & $\mathrm{n}$ de $\mathrm{m}$ & elo & & & lección & de mo & & & Elección & $\mathrm{mc}$ & \\
\hline & $=\alpha$ & $\beta x_{i t}$ & $\varepsilon_{i}+\mu_{i t}$ & & & ${ }_{t}=\alpha_{i}+$ & $\beta x_{i t}$ & & & $i t=\alpha$ & $-\beta x_{i t}$ & \\
\hline
\end{tabular}

(M1): Regresión agrupada con intercepto común, (White cross-section standard error \& covariance).

(M2): Efectos Fijos, variables dummy en sección cruzada, (White cross-section standard error \& covariance).

(M3): Efectos Fijos, variables dummy en periodo, (White period standard error \& covariance).

(M4): Efectos aleatorios, (White period standard error \& covariance). 
Los resultados de estimación reportados en la Tabla número 6 corresponden a cuatro distintas especificaciones y sobre las cuales se elige el modelo estándar más apropiado con base a pruebas econométricas fundamentales. En el caso particular en donde la variable dependiente es el personal ocupado total, la prueba $\mathrm{F}$ restringida que contrasta el modelo con intercepto común con el de efectos fijos en el tiempo, sugiere que este último es mejor. Sin embargo, la prueba de Hausman que contrasta el modelo con efectos fijos en el tiempo y el de efectos aleatorios, indica que el modelo más adecuado es el de efectos aleatorios. La prueba de BreuchGodfrey, también apunta a que el modelo de efectos aleatorios es mejor que el del intercepto común, pues se rechaza la hipótesis de que los efectos son igual a cero. En este sentido, la regresión que mejor explica $L 1_{i t}$ corresponde al modelo $M 4$ de efectos aleatorios.

Las estimaciones sugieren que la elasticidad demanda de trabajo-producto, es positiva y la elasticidad remuneraciones reales-demanda de trabajo es negativa. En ambos casos, se determinan que el signo de los parámetros es concordante con lo que postula la teoría keynesiana y neoclásica respectivamente. Sin embargo, es apropiado resaltar que la evolución del PIB tiene un mayor impacto en el empleo que la propia reducción de las remuneraciones. Además, esta última variable no es estadísticamente significativa a un nivel estándar del 95\% de confianza. El coeficiente de la elasticidad demanda de empleo-producto es de 0.62 indicando que si el producto interno bruto se incrementa en un $1 \%$, la demanda de empleo aumentará en promedio en $0.62 \%$. Si bien la relación es menos que proporcional, se admite que la sensibilidad del empleo es marcada con respecto al nivel de actividad económica. Por consiguiente, cualquier esfuerzo por generar empleo, necesariamente debe involucrar acciones, estrategias, planes y programas que estén orientados a fortalecer el crecimiento económico. Un país con bajas tasas de crecimiento, no sólo enfrentará restricciones para potenciar la demanda de empleo formal, sino que se crearan las condiciones para que siga creciendo la informalidad laboral, los niveles de pobreza y la desigualdad en los ingresos de los hogares.

Para el mismo segmento de la demanda total de empleo (obreros y empleados), se encuentra que la productividad laboral tiene un efecto negativo sobre la demanda de trabajo. El coeficiente de -0.454 , sugiere que si la productividad se incrementa en un $1 \%$, la demanda de empleo total disminuirá en $0.45 \%$. Si bien dicha magnitud, es menor en valor absoluto a la reportada para el producto interno bruto, se reconoce que muestra una importante sensibilidad ante los cambios porcentuales en la productividad. En este contexto, es pertinente formularse la interrogante de si los aumentos en la productividad son buenos o malos. Se sostiene que el mejoramiento de la productividad es bueno, ya que puede contribuir a detonar el crecimiento económico a largo plazo y también es un factor de competitividad en un ambiente de competencia interna y externa. Sin embargo, debe considerarse que los obreros que constituyen la fuerza de trabajo no especializada, tienen un peso mayor en el personal ocupado total. Por ello, se infiere que si mejora la productividad laboral, lo que disminuye fundamentalmente es la demanda de obreros, dado el peso relativo que tienen en la demanda de empleo total. Por esta y otras razones que se han expuesto previamente, es que se justifica estimar funciones de demanda laboral para los dos segmentos de la fuerza de trabajo (obreros y empleados). Se entendería que el efecto negativo de la productividad sobre la demanda del empleo total, se estaría explicando en parte, por lo que se ha venido discutiendo en la literatura y que tiene que ver con un proceso de cambio tecnológico sesgado que desfavorece la demanda del trabajo menos calificado.

Con relación a las exportaciones, también se determina que es una variable relevante. Aunque se precisa que la magnitud de su coeficiente es inferior al del producto interno bruto y 
de la productividad, revela que si las exportaciones de la industria manufacturera se incrementan en un $1 \%$, la demanda de empleo total crecería en $0.134 \%$. Desde esta perspectiva, se plantea que la dinámica del sector externo es fundamental para explicar la demanda de trabajo. Contar con un sector exportador fuerte no sólo fortalece la demanda agregada de una economía o puede convertirse en una fuente importante de generación de divisas, sino que también puede impulsar el empleo en una coyuntura en donde el mercado interno puede estar contraído. Por tanto, promover el sector externo restándole importación al mercado interno o viceversa, no debe ser un proceso mutuamente excluyente o un dilema en el terreno de la política económica, sino más bien, dos procesos complementarios e indispensable en una estrategia de generación de empleo a mediano y largo plazo.

En el caso del segmento de los obreros, también se realizaron las pruebas econométricas respectivas para decidir qué tipo de modelo de panel es el más adecuado para explicar la variable $L 2_{i t}$. La prueba $\mathrm{F}$ restringida con efectos fijos en el tiempo pero variante en la unidad de corte transversal, sugiere que es mejor el modelo de efectos fijos en contraste con el de intercepto común o regresión agrupada. Por su parte, la prueba de Hausman sugiere que la hipótesis nula de que los efectos aleatorios no están correlacionados con las variables Xs, se rechaza, determinando así, que es mejor estimar efectos fijos que efectos aleatorios. Finalmente, el contraste de Bruch - Pagan, demuestra que es mejor un modelo de efectos aleatorios que de efectos fijos. Una vez evaluando estas pruebas en conjunto y la significancia de las variables y del modelo, se opta por elegir el modelo M2 que corresponde a una especificación de efectos fijos con variables dummy para los cortes transversales (véase Tabla 6). Se constata que, de todos los coeficientes, la elasticidad demanda de trabajo - producto es la más elevada, siendo igual a 0.66. Al igual que en el modelo anterior, se prescribe que el crecimiento real de la economía mexicana, es un factor importante que explica la demanda de trabajo (obreros). Se destaca que es imprescindible que el producto interno bruto real se incremente, si se desea que la demanda de fuerza de trabajo menos especializada también lo haga, puntualizando que el crecimiento de la actividad económica seguramente se debería de registrar en aquellos sectores ligados más hacia actividades tradicionales que no necesariamente demandan de fuerza de trabajo especializada o que exhiben un menor desarrollo tecnológico. En este caso la variable relacionada con los costos de la mano de obra, ya no son las remuneraciones totales, sino los salarios reales, cuyo coeficiente es de -0.199 , lo que sugiere que si se incrementan en $1 \%$, la demanda de obreros disminuiría en $0.199 \%$, aclarando que es una serie que es estadísticamente significativa sólo al $90 \%$ de confianza, pero mucho más relevante que para el caso del personal ocupado total.

Con relación a la productividad, el modelo de efectos fijos reporta una elasticidad de -0.46 , refiriendo que si se incrementa en $1 \%$, entonces la demanda de obreros en la industria manufacturera disminuirá en promedio $0.46 \%$. Este dato es relevante en el sentido, de que los mejoramientos en la productividad no se acompañan de una mayor demanda de obreros, sino que por el contrario, los esfuerzos que se logren hacer en los distintos sectores, tendrán en promedio un efecto negativo en la demanda de trabajo menos calificado. Revertir el efecto, desde luego que no supondría desalentar la productividad, sino más bien, fortalecer los niveles de capacitación, adiestramiento y especialización en general de los obreros, a fin de que su desempeño y demanda, sea consistente con los mejoramientos de la productividad laboral. En el caso de las exportaciones manufactureras se obtiene un coeficiente de 0.144 , que da cuenta de que si crecen en $1 \%$, entonces la respuesta de la demanda de obreros se incrementará 
en $0.144 \%$. Si bien es la variable que reporta la magnitud más pequeña del conjunto de los coeficientes, también resulta alentador concebir que un mejoramiento de las exportaciones manufactureras se puede traducir en un crecimiento positivo de la demanda de empleos menos calificados, aunque se esperaría que el sector externo, tuviese un efecto más notorio en la demanda de trabajo calificado, como en efecto se confirma en los resultados siguientes.

Finalmente en lo que concierne a la función de los empleados en aproximación a lo que puede considerarse demanda de trabajo calificado, el análisis global de los estadísticos y pruebas econométricas, sugiere que la especificación idónea para modelar la variable $L 3_{i t}$, es un modelo de efectos fijos en el tiempo y variante en cada unidad de sección cruzada, M2. Los resultados de esta regresión se distinguen de los dos modelos previamente elegidos en un aspecto fundamental, todas las variables son relevantes. Los sueldos a diferencia de las remuneraciones y salarios, son estadísticamente significativos al 95\% de confianza y además su coeficiente de -0.487 es muy superior al del personal ocupado total de -0.086 y de los obreros de -0.199 . Esto significa que si los sueldos en la industria manufacturera se incrementan en $1 \%$, en promedio la demanda de empleados disminuirá en $0.487 \%$. En este marco de análisis, se observa que los costos de la fuerza de trabajo sí juegan un rol importante en la demanda laboral de la industria de la manufactura. Al tratarse de un segmento más especializado, se infiere que mayores sueldos pueden mermar la competitividad de la industria y con ello reducirse el potencial de demanda. Sin embargo, se debe enfatizar que una estrategia de competitividad basada sostenidamente en el largo plazo en bajos costos laborales, no es deseable, por el contrario se deben mejorar otros aspectos relacionados con la diferenciación del producto, o bien, alentar un mayor nivel de habilidades y así considerar la posibilidad de pagar salarios de eficiencia. Otro aspecto que se deriva de los resultados, es que contemplando las tres estimaciones a las que se ha aludido, (personal total, obreros y empleados), el incremento de los sueldos tiene un efecto menor sobre la reducción de empleados que el que tienen las remuneraciones y salarios sobre el personal ocupado total y obreros respectivamente. Hecho que se entendería por el grado de especialización que representa cada segmento y sobre todo el de los obreros y empleados en forma desagregada.

Con relación a la variable de actividad económica medida a través del producto interno bruto real de la manufactura, se aprecia que es significativa y con signo positivo. El coeficiente indica que si se incrementa en $1 \%$ el PIB, la demanda de trabajo especializado (empleados), se incrementará en $0.454 \%$. Cabe notar, sin embargo, que a diferencia de las dos estimaciones previas, para el caso de personal ocupado total y obreros, el efecto del crecimiento económico de la manufactura es menor al registrado en los casos anteriores. La elasticidad demanda de empleo-exportaciones manufactureras, sugiere que si se incrementa la actividad de exportación en un $1 \%$, la demanda de trabajo especializado aumentará en promedio $0.10 \%$. En este caso se constata que hay una estrecha relación entre desempeño del sector exportador manufacturero y empleo con mayor grado de especialización, un vínculo que no resulta del todo sorprendente, si se considera que justamente el sector externo es demandante de mayores habilidades laborales. Por su parte, la variable productividad sigue teniendo un impacto negativo sobre la demanda de empleo, aunque menor al que se reportan en las dos regresiones previas. Es decir, se determina que mejoramientos de la productividad, no sólo reducen la demanda de obreros, sino también la de empleados, pero en menor proporción, tal como se esperaría, pues las actividades manufactureras más productivas, del algún modo demandan fuerza de trabajo más especializada. 
Como reflexión derivada del contraste empírico, es menester tomar en cuenta que la elección de cada uno de los modelos, no se realizó de manera arbitraria, sino con base a pruebas que sugiere la teorlía econométrica estándar. Se insiste en que el propósito de correr distintas regresiones para cada segmento del mercado laboral, responde al interés de evaluar distintas posibilidades de estimación y de someterlas a pruebas convencionales que permiten discriminar dada la naturaleza de los datos. En los tres casos de estudio se ha descartado la estimación de panel más restrictiva que supone que los interceptos son constantes respecto a subsectores y el tiempo. Por otra parte, tomar en cuenta que la dimensión de la información no corresponde estrictamente a un macro-panel. Por tanto, evitar mermar los grados de libertad es deseable a fin de no debilitar el proceso de estimación e inferencia estadística. Por esta razón es que sólo se contemplan interceptos diferenciales en los modelos de efectos fijos (obreros y empleados). En el caso del personal ocupado total, que se estima un modelo de efectos aleatorios, el intercepto para cada unidad de análisis estaría dado por un valor medio de intercepto más un término de error aleatorio. Por consiguiente, en los modelos estimados se han considerado cambios en los coeficientes de intersección a través de variables dummy aditivas que arrojan interceptos diferenciales. En el caso de los coeficientes de las pendientes se han mantenido constantes, debido fundamentalmente a que no se dispone de un macro-panel. Hacerlo implicaría incluir variables dummy interactivas, lo que arrojaría números coeficientes de pendientes diferenciales, con la implicación de que se reducirían demasiado los grados de libertad $N T-K$, generándose, además, un posible problema de multicolinealidad tal como postula la teoría de datos de panel (Wooldridge, 2007).

\section{Conclusiones}

La industria manufacturera ha demostrado ser uno de los sectores más importantes de la economía mexicana y representa una parte importante del producto y el empleo total. A partir de la apertura de la economía nacional, el desempeño de la industria manufacturera se ha convertido en un sector preponderante. Sin embargo, también se observa que su participación en el total de la actividad económica y el empleo generado, ha venido exhibiendo una evolución menos dinámica. También habría que considerar que ha sido un sector que se ha visto afectado sensiblemente por las secuelas de la crisis de 2008-2009 que se suscitó en Estados Unidos y que, sin duda, tuvo repercusiones internacionales de gran calado.

Se podría afirmar que un proceso de cambio tecnológico que incide en la mejora de la productividad, podría derivar en una menor demanda de trabajadores. Sin embargo, los resultados sugieren que el efecto adverso se produce con mayor notoriedad en el segmento de la fuerza de trabajo obrera que en el de los empleados, que se considera poseen un grado de mayor especialización. En este sentido, se advierte sobre la necesidad de que el segmento de los obreros, logre mejorar sus niveles de productividad laboral, a fin de verse menos afectados por la evolución del cambio técnico y lo que supone en materia de productividad en el mercado laboral. También se observa que el crecimiento del personal ocupado total, así como el conjunto de obreros y empleados por separado, es muy sensible al comportamiento del producto interno bruto manufacturero como indicador de actividad económica. Se determina que la actividad económica interna, es un determinante fundamental de la demanda de empleo, incluso más que los niveles salariales como supone la teoría estándar. En este sentido, los retos que la economía mexicana tiene para lograr un mayor crecimiento económico en el seno de la manufactura, son de carácter urgente, lo que implica no sólo diversificar el mercado externo, sino también 
impulsar el mercado interno a través de una mayor inversión productiva tanto pública como privada.

En contraste, se ha determinado que las remuneraciones, salarios y sueldos reales, si bien arrojan un coeficiente acorde a lo que se esperaba respecto a su relación con el personal ocupado total, obreros y empleados, no resultan variables estadísticamente relevantes en el modelo, con excepción del caso de los empleados. Este resultado sugiere que la evolución del empleo no está en esencia determinada por los costos de la fuerza de trabajo, o por aquellas acciones de flexibilización del mercado de trabajo. Por el contrario, se demuestra que un mercado de trabajo en franca recuperación está más vinculado al grado de desempeño económico. Por tanto, para alcanzar mayores tasas de ocupación en la industria manufacturera, es imprescindible un mayor ritmo de crecimiento económico en el sector de la manufactura y en general mejorar el bienestar de los hogares a través del consumo y acceso a mayor infraestructura que provea de mejores servicios públicos. Los resultados deben conducir a reflexionar en torno a los retos que supone estimular el crecimiento económico. Los cuales se pueden situar tanto a escala nacional como regional y local. En los distintos niveles de la administración pública, se deben desarrollar y monitorear planes de desarrollo empresarial que favorezcan la actividad económica tomando en consideración las vocaciones productivas locales y regionales, aprovechando y desarrollando proceso de innovación y los acervos de capital humano. Fomentar el consumo interno y la inversión productiva aunada al desarrollo de infraestructura pública, puede crear condiciones para detonar el ambiente de negocios, los planes de inversión de mediano y largo plazo y la competitividad sectorial. Todos estos son elementos indispensables para mejorar la actividad económica y fomentar el crecimiento del empleo formal y de calidad. Finalmente se debe ponderar que las exportaciones de la industria manufacturera también son una variable detonante de empleo y que fortalecer el mercado interno no supone, desanimar la actividad exportadora, sino que por el contrario, seguir fomentándola y ver ambos procesos como complementarios.

\section{Referencias}

Almonte, L. Carbajal, S. Y. Valverde, V. C. (2013). El empleo manufacturero en el estado de México: estimación por división de actividad económica, 1999-2008. Economía UNAM, vol. 10, núm. 29, 56-73. https://doi.org/10.1016/ s1665-952x(13)72195-9

Argoti (2011). Algunos elementos sobre la teoría clásica del empleo y la versión keynesiana. Tendencia, revista de la Facultad de Ciencias Económicas y Administrativas. Universidad de Nariño, vol. XII, no. 2, segundo semestre. Disponible en: https://dialnet.unirioja.es/servlet/articulo?codigo=3854586 y consultado: 05/03/2016.

Banco Mundial (2012). Informe sobre el desarrollo mundial 2013. Panorama general: Empleo. Washington, DC: Banco Mundial. Licencia: Creative Commons Atribucion CC BY 3.0. Disponible en: http://siteresources.worldbank. org/EXTNWDR2013/Resources/8258024-1320950747192/8260293-1322665883147/Overview_Spanish.pdf y consultado: 9/9/2015.

Bencosme G. P. (2008). Estimación de la demanda por trabajo en la economía dominicana. Unidad Asesora de Análisis Económico y Social, Secretaria de Estado de Economía, Planificación y Desarrollo, texto de discusión no. 12, 1-20. Disponible en: http://economia.gob.do/despacho/unidad-asesora-de-analisis-economico-y-social/textos-de-discusion/ y consultado: 24/11/2015.

Castillo C. M. (2006). Demanda laboral industrial en el área metropolitana de Cali: Un análisis entre 1995 y 2001. Revista Sociedad y Economía, núm. 11, julio-diciembre, 40-64. Disponible en: www.redalyc.org/pdf/996/99616177002. 
pdf y consultado: 07/10/2015. Dussel, E. (2003). Características de las actividades generadoras de empleo en la economía mexicana (1988-2000). Investigación Económica, vol. LXII, núm. 243, enero-marzo, 123-154. Disponible en: www.redalyc.org/articulo.oa?id=60124304 y consultado: 10/03/2016. Fajnzylber, P. y Maloney, W. (2005). Labor demand and trade reform in Latin America. Journal of International Economics, 66, 423-446. https:// doi.org/10.1016/j.jinteco.2004.08.002

Félix G., y Castro, L.D. (2015). Demanda laboral en las industrias integradas a cadenas de valor internacionales. Un análisis regional con panel dinámico no estacionario para el caso de México. Centro de Investigaciones Socioeconómicas. Universidad Autónoma de Coahuila-México. Disponible en: https://www.researchgate.net/publication/291829419_Felix-Castro2015_ICRS y consultado: 17/03/2016.

Hamermesh, D. (1993). Labor Demand. Princeton, Princeton University Press, 1993.

Hamermesh, D. S. (2004). Labor Demand in Latin America and the Caribbean: What Does It Tell Us? In Law and employment: Lessons from Latin America and the Caribbean, cords. James J. Heckman y Carmen Pages. Chicago Scholarship Online. https://doi.org/10.7208/chicago/9780226322858.003.0012

Hsiao, C. (2003). Analysis of panel data. Cambridge University Press. 2nd ed., United Kingdom.

INEGI (2013). Encuesta Mensual de la Industria Manufacturera 2013. Instituto Nacional de Estadística y Geografía. México, INEGI.

INEGI (2012). Cálculo de los índices de productividad laboral y del costo unitario de la mano de obra. Instituto Nacional de Estadística y Geografía. México.

Isaza, J. y Meza, C. (2004). La demanda de trabajo Teoría y evidencia empírica para el caso colombiano. Revista Equidad y Desarrollo, núm. 2. Julio, 35-64 https://doi.org/10.19052/ed.392

Lanteri, L. (2013). Determinantes económicos del nivel de empleo. Alguna evidencia para Argentina. Ensayos Revista de Economía, vol. XXXII, núm. 1, 73-100. Disponible en: https://ideas.repec.org/a/ere/journl/vxxxiiy2013i1p73-100.html y consultado: 2/03/2016.

Lechuga, M. J. y Varela, O. M. (2001). Empleo Manufacturero en México, 1990-1998. Análisis económico, vol. XVI, núm. 33, segundo semestre, 2001, 215-234. Disponible en: http://www.redalyc.org/pdf/413/41303308.pdf y consultado: 26/02/2016.

Loría, E. (2010). Sobre el lento crecimiento económico de México. Una explicación estructural. Investigación Económica, vol. LXVIII, 270, octubre-diciembre de, 37-68. http://dx.doi.org/10.22201/fe.01851667p.2009.270.16681

Loría, E., \& Brito, L. (2005). El impacto de la inversión extranjera directa en el empleo sectorial en México: Un análisis de prospección. Análisis económico, vol. XX, núm. 44, segundo cuatrimestre, 5-34. Disponible en: http://www. redalyc.org/pdf/413/41304402.pdf y consultado: 24/02/2016.

Pindyck R. y Rubinfeld D. (2001). Econometría: modelos y pronósticos. Cuarta edición, editorial Mc Graw-Hill. México D.F.

Martínez C. Morales G. y Valdés R. (2001) Cambios Estructurales en la demanda por trabajo en Chile. Economía Chilena, vol. 4, núm. 2, 5-25. Disponible en: https://dialnet.unirioja.es/servlet/articulo?codigo=965028 y consultado: 09/09/2015.

McConnell C. Brue S. y Macpherson D. (2003). Economía laboral, Sexta Edición. (Contemporary Labor Economics) Traducción al español de Esther Rabasco y Luis Toharia, McGraw-Hill, Madrid.

Medina, C.; Posso, C.; Tamayo, J. y Monsalve, E. (2012). Dinámica de la demanda laboral en la industria manufacturera colombiana 1993-2009: Una estimación panel VAR. Borradores de economía Núm. 694. Banco de la Republica. Disponible en: http://www.banrep.gov.co/docum/ftp/borra694.pdf y consultado: 07/10/2015.

Moreno, B. J. C. (2016). Política macro e industrial para un cambio estructural y crecimiento: gran pendiente de la economía mexicana. Revista problemas del desarrollo. Revista latinoamericana de economía, vol. 47, núm. 185, jun, 59-80. https://doi.org/10.1016/j.rpd.2015.10.013

Peralta, E. (2010). Perspectiva Laboral en Mexico 2008-2030. Comercio Exterior, 60(3), 195-208. Disponible en: http:// revistas.bancomext.gob.mx/rce/magazines_en/123/2/195_Peralta_LABORAL.pdf y consultado: 25/02/2016.

Ríos J. y Carrillo S. (2014). El empleo calificado y no calificado en la manufactura de México ante la crisis de 2009. Economía, Sociedad y Territorio, vol. XIV, núm.46, septiembre-diciembre, 687-714. https://doi.org/10.22136/ est002014393 
Roberts M. y Skoufias E. (1997). The Long-Run Demand for Skilled and Unskilled Labor in Colombian Manufacturing Plants. The Review of Economics and Statistics, 79(2), may, 330-334. https://doi.org/10.1162/003465397556700

Ros, J. (2005). El desempleo en America Latina desde 1990. CEPAL Serie estudios y perspectivas. Unidad de desarrollo economico. Serie Estudios y Perspectivas, núm29, 1-34. Disponible en: https://repositorio.cepal.org/handle/11362/4949 y consultado: 13/03/2015.

Ruiz, D. C. (2005). El reto del empleo en Mexico. Comercio Exterior, 55(1), 6-15. Disponible en: http://revistas. bancomext.gob.mx/rce/magazines/74/2/RCE.pdf y consultado: 10/09/2015.

Pindyck R.S. y Rubinfeld D.L. (2001). Econometría, modelos y pronósticos. Cuarta edición, Mc Graw Hill, 1-639.

Samaniego, B. N. (2014). La participación del trabajo en el ingreso nacional: el regreso a un tema olvidado. Economiaunam, 11(33), 52-77. https://doi.org/10.1016/s1665-952x(14)72181-4

Tangarife, Carmen Lucía, (2013). La economía va bien pero el empleo va mal: factores que han explicado la demanda de trabajo en la industria colombiana durante los años 2002-2009. Perfil de Coyuntura Económica, núm. 21, enero-junio, 2013, pp. 39-61 Universidad de Antioquia Medellín, Colombia. Disponible en: http://www.redalyc.org/ pdf/861/86129819003.pdf y consultado: 16/09/2015.

INEGI (2013). Síntesis Metodológica de la Encuesta Mensual de la Industria Manufacturera.

Wooldridge M. Jeffrey (2007). Introducción a la econometría, un enfoque moderno. 2da edición, editorial Thomson. España. 